\title{
Quantification of SARS-CoV-2 neutralizing antibody by a pseudotyped virus-based assay
}

\author{
Jianhui Nie $\oplus^{1,6}$, Qianqian $\mathrm{Li}^{1,2,6}$, Jiajing $\mathrm{Wu}^{1,3,6}$, Chenyan Zhao ${ }^{1}$, Huan Hao ${ }^{1}$, Huan Liu ${ }^{1}$, Li Zhang ${ }^{1}$, \\ Lingling Nie ${ }^{1}$, Haiyang Qin ${ }^{1}$, Meng Wang ${ }^{1}$, Qiong Lu', Xiaoyu Li ${ }^{1}$, Qiyu Sun ${ }^{1}$, Junkai Liu ${ }^{1}$, \\ Changfa Fan ${ }^{4}$, Weijin Huang $\mathbb{1}^{1 \bowtie}$, Miao Xu ${ }^{5 \bowtie}$ and Youchun Wang $\mathbb{1}^{1,2 \bowtie}$
}

Pseudotyped viruses are useful virological tools because of their safety and versatility. On the basis of a vesicular stomatitis virus (VSV) pseudotyped virus production system, we developed a pseudotyped virus-based neutralization assay against severe acute respiratory syndrome coronavirus 2 (SARS-CoV-2) in biosafety level 2 facilities. Compared with the binding antibody test, the neutralization assay could discriminate the protective agents from the antibody family. This protocol includes production and titration of the SARS-CoV-2 S pseudotyped virus and the neutralization assay based on it. Various types of samples targeting virus attachment and entry could be evaluated for their potency, including serum samples derived from animals and humans, monoclonal antibodies and fusion inhibitors (peptides or small molecules). If the pseudotyped virus stock has been prepared in advance, it will take $\mathbf{2}$ days to get the potency data for the candidate samples. Experience in handling cells is needed before implementing this protocol.

More than 18 million cases of the coronavirus disease 2019 (COVID-19), which is caused by severe acute respiratory syndrome coronavirus 2 (SARS-CoV-2), had been diagnosed globally by 6 August 2020. Therapeutics and vaccines for COVID-19 are urgently needed. Because of its high pathogenicity and infectivity, all test procedures employing live viruses to evaluate the products' potency have had to be handled under biosafety level (BSL) 3 facilities, which has hindered the development of products. Standardized in vitro potency methods are urgently needed to evaluate antiviral products in pre-clinical and clinical phases. In addition, detection of neutralizing antibodies against SARS-CoV-2 would be helpful to understand the status of the protective immune response among COVID-19 patients and asymptomatic cases ${ }^{1}$.

SARS-CoV-2 is a single-stranded positive-sense RNA virus, belonging to the $\beta$-coronaviruses of the coronaviridae family ${ }^{2}$. It is one of the largest known RNA viruses with a genome length of $\sim 29.8 \mathrm{kbp}^{3-5}$. The first two-thirds of the genome, which consists of non-structural genes, mainly encodes enzymes related to virus replication, and the latter one-third sequentially encodes four structural proteins: spike protein $(S)$, small envelope protein $(E)$, matrix protein $(M)$ and nucleocapsid protein $(N)^{6}$. Among them, $S$ protein contains the binding region of the virus receptor, which mediates the adsorption and entry of the virus into cells. The $S$ protein of coronaviruses is the main protein that stimulates the immune system to produce neutralizing antibodies after the virus infects the body ${ }^{7-10}$. Various monoclonal neutralizing antibodies against the $\mathrm{S}$ protein of coronaviruses have been isolated and proven to be effective in animal models ${ }^{11-14}$. In addition, peptide fusion inhibitors ${ }^{15}$ or small molecules that block host cell entry ${ }^{16}$ have also been found to be effective in other coronavirus studies, which also targeted the $S$ protein ${ }^{7}$.Thus, the $S$ protein is the main target for the design of SARS-CoV-2 vaccines and some therapeutic products.

Development of the protocol and production of a pseudotyped virus

The SARS-CoV-2 S pseudotyped virus is prepared by using a VSV pseudotyped virus packaging system $^{17}$, which has been previously used to generate various pseudotyped viruses, such as

1Division of HIV/AIDS and Sex-transmitted Virus Vaccines, Institute for Biological Product Control, National Institutes for Food and Drug Control (NIFDC) and WHO Collaborating Center for Standardization and Evaluation of Biologicals, Beijing, China. ${ }^{2}$ Graduate School of Peking Union Medical College, Beijing, China. ${ }^{3}$ Wuhan Institute of Biological Products, Wuhan, China. ${ }^{4}$ Division of Animal Model Research, Institute for Laboratory Animal Resources, National Institutes for Food and Drug Control, Beijing, China. ${ }^{5}$ Institute for Biological Product Control, National Institutes for Food and Drug Control and WHO Collaborating Center for Standardization and Evaluation of Biologicals, Beijing, China. ${ }^{6}$ These authors contributed equally: Jianhui Nie, Qianqian Li, Jiajing Wu. ${ }^{\circledR e}$-mail: huangweijin@nifdc.org.cn; xumiaobj@126.com; wangyc@nifdc.org.cn 


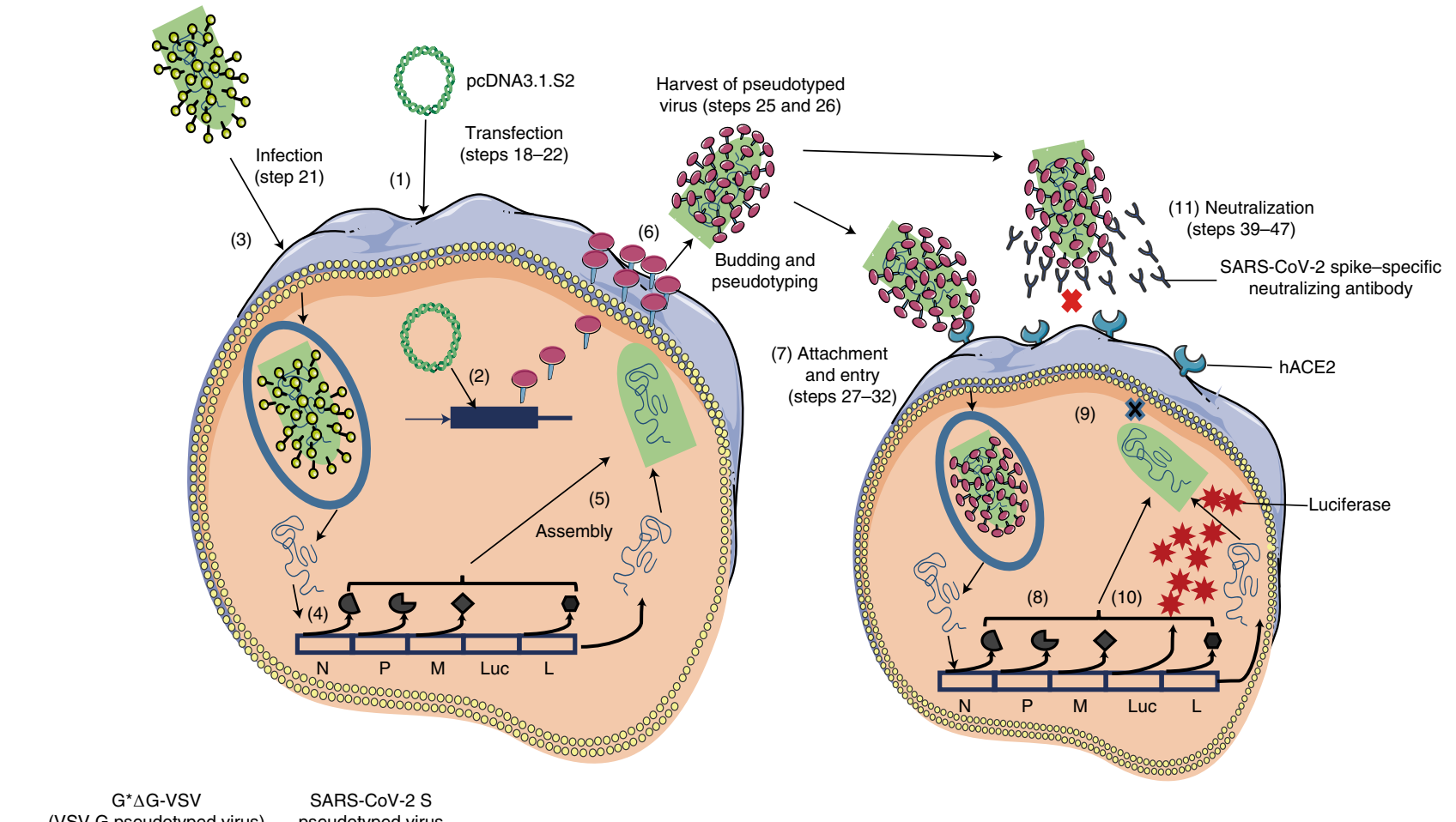

(VSV G pseudotyped virus) pseudotyped virus
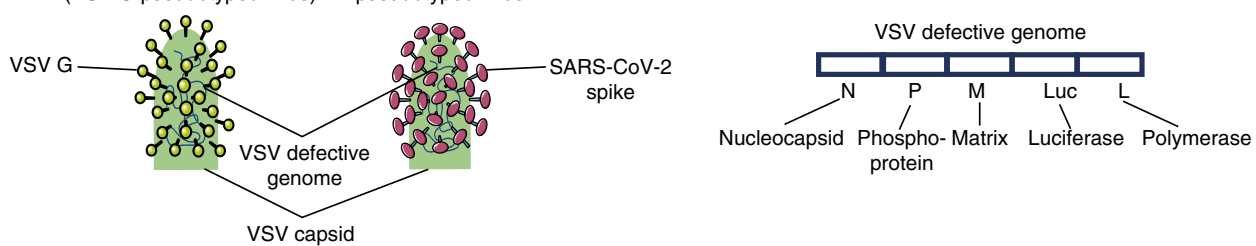

Fig. 1 | Schematic diagram of SARS-CoV-2 pseudotyped virus production and neutralization assay based on a VSV pseudotyped virus production system. 293T cells are transfected with SARS-CoV-2 S protein expression plasmid (pcDNA3.1.S2) (1), which is transcribed and expresses full-length $S$ protein that is transferred to and anchored in the cell membrane (2). At the same time, 293T cells are infected with VSV G pseudotyped virus ( $\mathrm{G}^{\star} \Delta \mathrm{G}-\mathrm{VSV}$ ), which enters the cells by using the VSV G protein on the surface of the particle and provides a defective VSV genome (3). After infection, the uncoated $\Delta G$-VSV genome expresses all the enzymes and structural proteins $(L, M, P$ and $N)$ from the VSV genome except $G$ protein (which has been replaced by a luciferase reporter gene, Luc) and completes partial genome replication (4). The expressed structural proteins and partially replicated genomes assemble into virus particles without an envelope (5), and the virus is released from the cells by budding, during which process the SARS-CoV-2 S protein expressed on the cell surface becomes the envelope protein of the pseudovirion. Thus, the pseudotyped virus with SARS-CoV-2 S protein incorporated on the envelope packages the defective VSV genome containing the reporter gene in its capsid (6). When these pseudotyped viruses are incubated with cells containing SARS-CoV-2 receptors, the pseudotyped viruses attach and enter the cells through the receptors on the cell surface (7). The pseudotyped viruses entering the cells will express all VSV proteins other than G protein, and these structural proteins will also be assembled into capsid protein particles with the replicated VSV defective genome (8). However, because there is no expression of surface proteins in this process, virus particles containing surface proteins cannot be formed (9). That is, the pseudotyped virus cannot replicate sequentially and has the ability of only a single-round infection. The VSV genome expresses the reporter gene Fluc, which can be detected after the addition of the substrate (10). If the pseudotyped virus is co-incubated with the sample containing neutralizing antibody or molecular inhibitors before cell infection, they will block the cell entry process (11). The number of blocked viruses can be determined by the results of chemiluminescence reduction, which reflects the level of neutralizing antibody or molecular inhibitors in the sample. (1)-(6) shows the process of production of SARS-CoV-2 pseudotyped virus. If the pcDNA3.1.S2 is replaced by pcDNA3.1.VSVG, the $\mathrm{G}^{\star} \Delta \mathrm{G}-\mathrm{VSV}$ can be amplified following these procedures.

Ebola virus $^{18}$, Nipah virus ${ }^{19}$, Hantaan virus ${ }^{20}$, Lyssavirus $^{21}$ and Rift valley fever virus ${ }^{17,22}$. The backbone of the pseudotyped virus comes from the VSV virus, in which the $G$ gene is replaced with the firefly luciferase (Fluc) reporter gene, and the $\mathrm{S}$ protein from SARS-CoV-2 is incorporated as the membrane protein on the surface of the VSV pseudotyped virus. The schematic procedure for preparation of SARS-CoV-2 pseudotyped virus and its subsequent use in a neutralization assay is shown in Fig. 1.

During the preparation of pseudotyped virus, 293T cells are transfected with the SARS-CoV-2 $S$ protein expression plasmid (Fig. 1). After transfection, the plasmid is transcribed, and full-length $S$ protein is expressed and becomes anchored in the cell membrane. At the same time, the cells are 
infected with VSV G pseudotyped virus (G* $\mathrm{G}^{*}$-VSV), which enters the cells by using the VSV G protein on the surface of the particle and provides a defective VSV genome. After infection, the uncoated $\Delta \mathrm{G}$-VSV genome expresses the enzymes and structural proteins from the VSV genome, except $\mathrm{G}$ protein, and completes genome replication. The expressed defective genome assembles into virus particles without an envelope, and the virus is released from the cells by budding (Fig. 1). During this process, the SARS-CoV-2 S protein expressed on the cell surface is anchored in the membrane of VSV particles and becomes the envelope protein of the pseudovirion. Thus, the SARS-CoV-2 pseudotyped virus packaged the defective VSV genome, within which the $G$ protein-expressing gene was replaced with a gene encoding Fluc. Bearing the $S$ protein in the membrane, the pseudovirion has the characteristics of SARS-CoV-2 infection ${ }^{23}$.

When the pseudotyped viruses are incubated with cells containing SARS-CoV-2 receptors, the pseudotyped viruses attach and enter the cells through the receptors on the cell surface. Both Huh-7 and Vero cells, which were used to isolate live virus ${ }^{24}$, can be infected efficiently by SARS-CoV-2 pseudotyped virus ${ }^{23}$. The pseudotyped viruses entering the cells will express all VSV proteins other than $G$, and these structural proteins will be assembled to form the capsid that packages the defective VSV genome. However, because there is no expression of surface proteins in this process, virus particles containing surface proteins cannot be formed. Thus, the pseudotyped virus cannot replicate sequentially and has the ability of only a single-round infection. The VSV genome not only expresses its own proteins, but also expresses the reporter gene Fluc, which can be detected after the addition of the substrate. The amount of pseudotyped virus in infected cells can therefore be determined by detecting a luminescence signal on a luminometer. There is a linear correlation between the value of chemiluminescence signal and the amount of infected pseudotyped virus ${ }^{23}$. If the pseudotyped virus is co-incubated with a sample containing neutralizing antibody or molecular inhibitors before cell infection, they will block the cell entry process. The number of blocked viruses can be determined by the results of chemiluminescence reduction, which reflects the level of neutralizing antibody or molecular inhibitors in the sample (Fig. 1).

\section{Overview of the procedure Timeline}

The SARS-CoV-2 pseudotyped virus neutralization test takes $\sim 10 \mathrm{~d}$ from the beginning of virus preparation to the completion of the neutralization test. The preparation of plasmids used in the production of pseudotyped viruses takes $3 \mathrm{~d}$ (Steps 1-14). When the cells are ready, the production process of the pseudotyped virus takes $3 \mathrm{~d}$ (Steps 15-26). The preparation process of VSVG pseudotyped virus is basically the same as that of SARS-CoV-2 pseudotyped virus. The titration of pseudotyped virus takes $2 \mathrm{~d}$ (Steps 27-38). The pseudotyped virus neutralization test takes $2 \mathrm{~d}$ (Steps 39-48).

\section{Plasmid preparation (Steps 1-14)}

Two plasmids, pcDNA3.1.VSVG and pcDNA3.1.S2, are needed in the preparation of SARS-CoV-2 pseudotyped viruses. The former is used to amplify the VSV virus vector $\mathrm{G}^{*} \Delta \mathrm{G}-\mathrm{VSV}$. G* $\Delta \mathrm{G}-\mathrm{VSV}$ can initially be obtained from Kerafast (EH1020-PM). However, it is only an aliquot with $300 \mu \mathrm{l}$ of working stock, which is not enough to generate the SARS-CoV-2 pseudotyped virus. Thus, it is necessary to generate additional working stocks by amplifying $G^{*} \Delta G-V S V$ in cells transfected with pcDNA3.1.VSVG before production of SARS-CoV-2 pseudotyped virus. To amplify the $\mathrm{G}^{*} \Delta \mathrm{G}-\mathrm{VSV}$, the cell is infected with $\mathrm{G}^{*} \Delta \mathrm{G}-\mathrm{VSV}$ stock received from Kerafast that lacks the G protein gene, and at the same time the cells are transfected with the plasmid pcDNA3.1.VSVG to provide the $\mathrm{G}$ protein, which enables the $\mathrm{G}^{*} \Delta \mathrm{G}-\mathrm{VSV}$ to complete its replication cycle and generates more $\mathrm{G}^{*} \Delta \mathrm{G}-\mathrm{VSV}$ (Steps 17-26). The latter plasmid is prepared by inserting the SARS-CoV-2 $S$ gene into the pcDNA3.1 plasmid by using BamH I and Xba I restriction sites, and used to deliver the SARS-CoV-2 $\mathrm{S}$ protein to the cell surface. To improve the expression efficiency of the SARS-CoV-2 S protein in mammalian cells, the $S$ gene (GenBank: MN908947) was codon-optimized to enhance expression in mammal cells ${ }^{23}$. Both plasmids are used to transfect cells. To avoid the effect of endotoxin on transfected cells, we suggest that the plasmid be extracted with endotoxinfree reagents. The concentration of the extracted plasmids should be $>0.5 \mathrm{mg} / \mathrm{ml}$. The quality of plasmids evaluated by spectrophotometer should meet the general requirements of DNA plasmids (Step 13). 


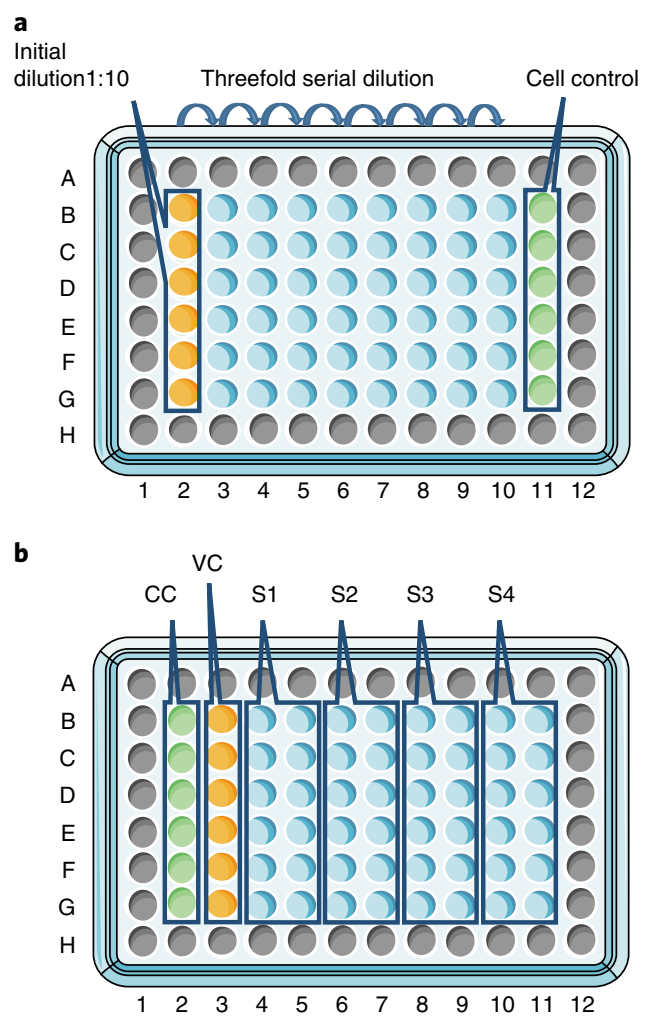

Fig. 2 | Plate design for pseudotyped virus titration (a) and neutralization assay (b). The gray wells indicate wells in which no samples were added, which are sealed with $250 \mu \mathrm{l}$ of sterilized water per well to avoid the effect caused by evaporation of the edge-well culture medium. The green wells indicate the cell control (CC) wells, in which only cells with culture medium are added. In the plate in $\mathbf{a}$, the orange wells are used as the initial dilution wells, in which pseudotyped viruses are diluted 10 -fold as the first dilution. The blue wells are used as the serial dilution wells. In the plate in $\mathbf{b}$, the orange wells are used as virus control (VC) wells, in which only pseudotyped viruses and cells are added with no samples. Blue wells are assigned as the sample wells, in which duplicates of each sample (S1-S4) are mixed with pseudotyped virus and incubated, followed by the addition of the cells.

\section{Cell transfection and pseudotyped virus production (Steps 15-26)}

SARS-CoV-2 pseudotyped viruses are prepared by SARS-CoV-2 S plasmid transfection providing membrane proteins on the surface of cells, and $G^{*} \Delta G-V S V$ infection providing genomes of VSV (Fig. 1). In the same way, G* ${ }^{*}$ G-VSV is amplified initially, by using VSVG plasmid instead of SARS-CoV-2 S plasmid. The first batch of cell supernatants are collected $24 \mathrm{~h}$ after infection and transfection, which is the first pseudotyped virus collection and can be stored at $2-8{ }^{\circ} \mathrm{C}$ for $24 \mathrm{~h}$. After adding the same volume of complete culture medium to the cells for another $24 \mathrm{~h}$, the cell supernatant is again collected, which is the second pseudotyped virus collection. Both the harvests of pseudotyped viruses are mixed, then divided into aliquots and cryopreserved at $-80{ }^{\circ} \mathrm{C}$, which is the bulk pseudotyped virus.

\section{Pseudotyped virus titration (Steps 27-38)}

When the pseudotyped virus is titrated, one tube of pseudotyped virus is taken out from $-80{ }^{\circ} \mathrm{C}$. Pseudotyped virus titration (Fig. 2a) is carried out by using 96-well plates. An initial 10-fold dilution is made followed by threefold serial dilutions for a total of nine dilutions, with each dilution being made in six replicate wells. After dilution, the target cells digested by trypsin are added, and a cell control without pseudotyped virus is also set up. The VSV genome packaged by the pseudotyped virus contains the Fluc gene. After the pseudotyped virus infects the target cells, the amount of pseudotyped virus infection can be characterized by adding substrate to detect the content of Fluc expressed. After incubation at $37{ }^{\circ} \mathrm{C}$ and $5 \%$ (vol/vol) $\mathrm{CO}_{2}$ for $24 \mathrm{~h}$, the luciferase substrate is added for chemiluminescence detection. The detected raw data are imported into the pseudoviral titration macro TCID50_SARS-CoV-2 (Supplementary Method 1 and Box 1) to calculate the pseudoviral titer and the recommended dilution for the neutralization test (Fig. 3a-c). The 50\% tissue culture 
Box 1 | How to use the macros to calculate titers of pseudotyped viruses and $\mathrm{EC}_{50}$ for samples

\section{Procedure}

1 Export the original data read by the instrument to an .xIsx file (Fig. 3a,d).

2 Open the macro file TCID50_SARS-CoV-2 (Fig. 3b, Supplementary Method 1) or Neutralization_SARS-CoV-2 (Fig. 3e, Supplementary Method 2).

3 Fill in the test information (Fig. 3b,e).

4 Copy the B2-G11 data in the original data .xIsx file. Paste into the original data area (Fig. 3b,e) in the macro file.

5 The titer of pseudotyped virus and the recommended dilution multiple (Fig. $3 \mathrm{C}$ ) and the $\mathrm{EC}_{50}$ value of the sample (Fig. 3f) are calculated automatically by the macros.

$\triangle$ CRITICAL The information colored in green in the assay parameter box ( $F i g .3 c, f$ ) can be modified as needed. If the test sample in the neutralization assay is a monoclonal antibody or entry inhibitor with known concentrations, you can change the 'Dilution Factor' in the assay parameter in macrofile

'Neutralization_SARS-CoV-2' to 1/3 (threefold serial dilution) before calculation. The concentration decreases threefold with the increase of one dilution. The 'Start Dilution' should be changed to the initial concentration of the corresponding sample.

infectious dose $\left(\mathrm{TCID}_{50}\right)$ of the pseudotyped virus is calculated according to the Reed-Muench method $^{25}$ in the titration macro template.

\section{Neutralization assay (Steps 39-48)}

The SARS-CoV-2 pseudotyped virus neutralization test begins with serial dilutions of the samples to be tested (Fig. 2b), which are then mixed with a certain amount $\left(325-1,300 \mathrm{TCID}_{50} / \mathrm{ml}\right)$ of pseudotyped virus. After that, the target cells are incubated for $24 \mathrm{~h}$, and the amount of pseudotyped virus entering the target cells is calculated by detecting the expression of luciferase, to obtain the neutralizing antibody content of the sample. Following this protocol, four samples (Fig. 2b) can be detected simultaneously in a 96-well plate. The cell control (CC) with only cells and the virus control (VC) with virus and cells are set up in each plate. When the raw data for control and samples are exported from the luminometer and pasted into the macro Neutralization_SARS-CoV-2 (Supplementary Method 2 and Box 1), the half maximal effective concentration $\left(\mathrm{EC}_{50}\right)$ is calculated for the tested samples (Fig. 3d-f).

\section{Advantages and limitations}

Because the $S$ protein of SARS-CoV-2 is considered the main antigen to induce the neutralizing antibody, several immune assays based on full-length $S$ protein ${ }^{26}$ or partial regions of $S$ protein such as the RBD region ${ }^{27,28}$ have been developed to evaluate the binding antibody for vaccines or in patients; however, it is difficult to predict the protective situations in patients, and the binding antibody may not be comparable between vaccines and patients. The most direct method to evaluate the neutralizing antibodies induced by SARS-CoV-2 vaccine is to use the infection inhibition test with live virus ${ }^{24}$, but the handling of live virus must be carried out in BSL-3 laboratories and is limited by experimental conditions and virus accessibility; thus, it is difficult to standardize between laboratories.

Binding assays with full-length or partial S protein detect all the antibodies targeting the coating antigen $^{26-28}$. They do not discriminate between neutralizing antibodies and non-neutralizing antibodies that rarely tend to be protective. The efficacy of the entry inhibitors cannot be evaluated by using the binding assay. Compared to binding assays, the assay based on pseudotyped virus can detect neutralizing antibodies and viral entry inhibitors, which can predict their function and efficacy. Compared to a neutralizing assay with live virus, this assay is safer and can be easily carried out in BSL-2 conditions because the pesudotyped viruses can replicate only for a single cycle after entering cells. Meanwhile, pseudotyped viruses carry reporter genes, which can be expressed after infection to facilitate detection. The quantitative detection of infected virus is realized by recording data objectively with a luminescence meter, which makes the assay amenable to high-throughput detection and easy to standardize.

The SARS-CoV-2 pseudotyped virus neutralization assay can, however, evaluate neutralizing antibodies only for S protein, not for other structural or non-structural proteins. Whether those proteins can induce neutralizing antibody is controversial ${ }^{29,30}$. After the pseudotyped virus infects the cells, it cannot complete the same life cycle as the live virus, and it is impossible to evaluate the inhibitory effect of the product on viral replication. The number of $S$ protein molecules expressed on the surface of the pseudotyped virus may affect the sensitivity of the neutralizing assay. Whether the number of $S$ protein molecules expressed on the surface of the pseudotyped virus is 


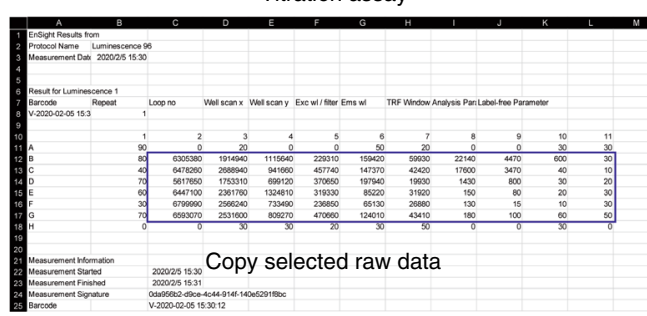

b

c

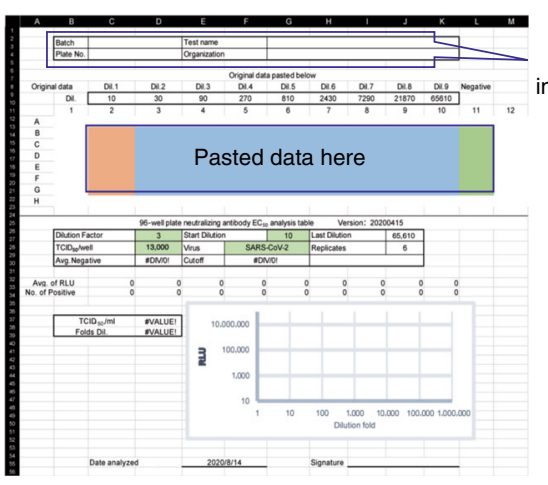

$\downarrow$

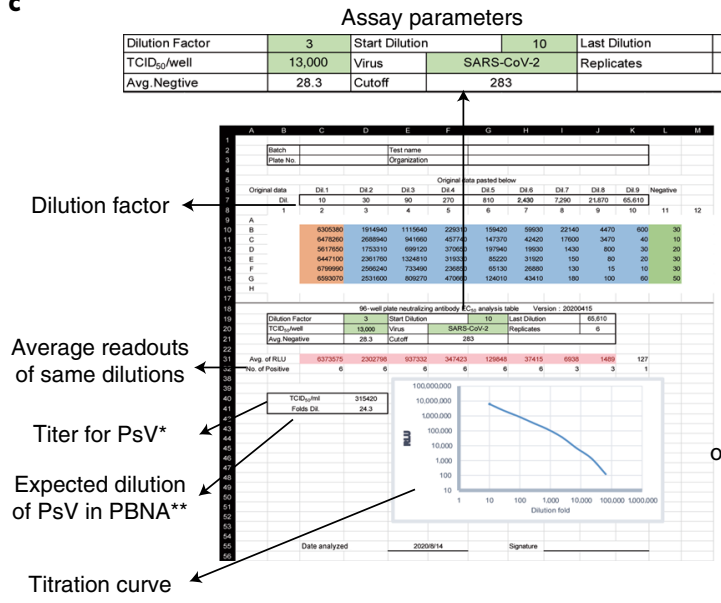

d

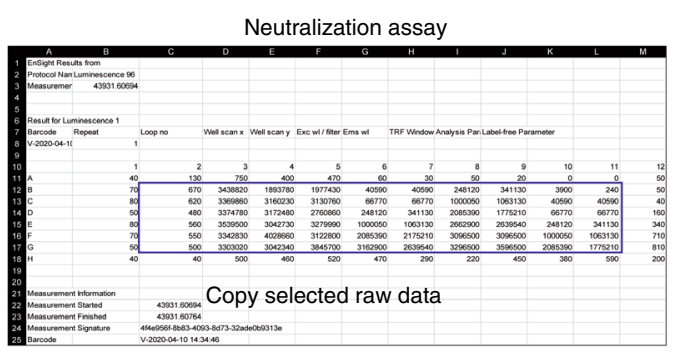

e
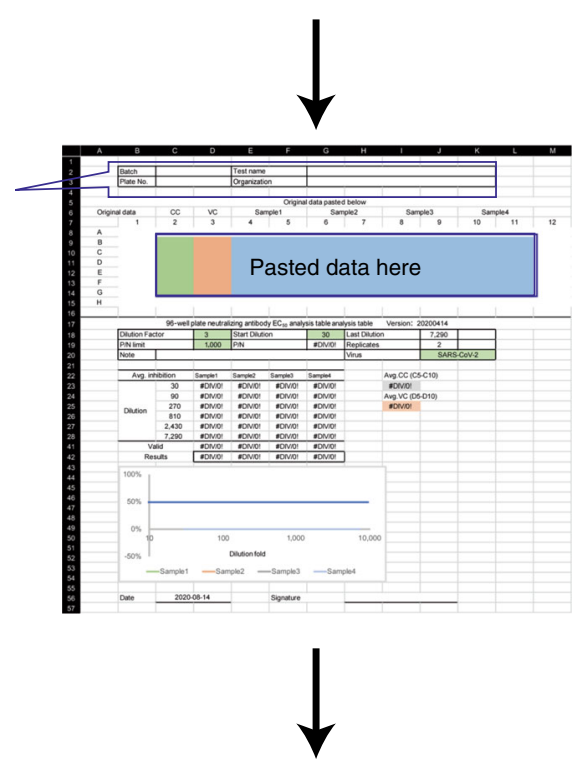

f
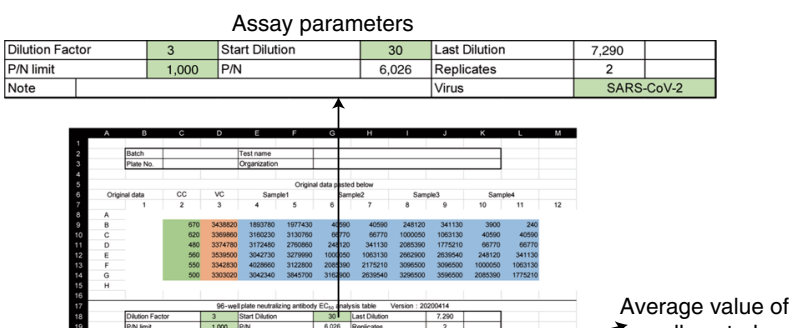

Dilution factor

Inhibition rate of infection (colored blue if $\geq 50 \%$ )

Neutralization curve

Fig. 3 I Screenshots showing the use of Excel macros to calculate TCID 50 (Supplementary Method 1 and Box 1) for titration assay and titers for neutralization assay (Supplementary Method 2 and Box 1). a, Luminescence readout data for a titration assay exported in the form of an Excel file. The selected raw data are indicated in a rectangle. b. The macro file for titration of the pseudotyped virus, TCID50_SARS-CoV-2 (Supplementary Method 1). A rectangle indicates where the raw data should be pasted. c, Calculated results in the TCID50_SARS-CoV-2 macro (Supplementary Method 1). d, Luminescence readout data for a neutralization assay exported in the form of an Excel file. The selected raw data are indicated in a rectangle. e, The macro file for the neutralization assay, Neutralization_SARS-CoV-2 (Supplementary Method 2). A rectangle indicates where the raw data should be pasted. f, Calculated results in the Neutralization_SARS-CoV-2 macro (Supplementary Method 2). Dil., dilution; EC 50 , half maximal effective concentration; P/N, average of virus control/average of cell control; ${ }^{*}$ PsV, pseudotyped virus; ${ }^{\star *}$ PBNA, pseudotyped virus-based neutralization assay; RLU, relative light unit; TCID50, 50\% tissue culture infectious dose; TRF, time-resolved fluorescence.

similar to that of the live virus also needs to be further studied. Therefore, in the process of developing the SARS-CoV-2 pseudotyped virus neutralization assay, it is necessary to carry out comparisons to the live virus to ensure its representativeness to the live virus detection method. Preliminary studies in our laboratory have shown a good correlation between pseudotyped virus 
neutralization assay and live virus neutralization assay (J.N., Q.L., J.W., W.H. and Y.W., unpublished observations, 2020).

\section{Applications}

The SARS-CoV-2 pseudotyped virus neutralization assay, developed in our laboratory ${ }^{23}$, has been used to screen monoclonal neutralizing antibodies ${ }^{31-33}$, characterize the neutralizing antibodies in convalescent patients ${ }^{1,27}$ and volunteers inoculated with candidate vaccine ${ }^{34}$ and evaluate potency of small molecular inhibitors (J.N., Q.L., J.W., W. Wang, W.H. and Y.W., unpublished observations, 2020). By replacing the $S$ protein expression plasmid, the cross-neutralization of antibodies to different mutant strains can be studied $^{35}$, and even the cross-neutralization between different coronaviruses can be investigated ${ }^{31,36}$. In addition to being used to evaluate products such as neutralizing antibodies and entry inhibitors in the process of virus infection, the assay can also be used to study virus cell tropism ${ }^{36}$ and receptor recognition patterns.

\section{Alternative methods}

In addition to the VSV-based pseudotyped virus system, lentivirus-based pseudotyped virus systems are also used in the preparation of SARS-CoV-2 pseudotyped virus ${ }^{37}$. The two systems differ in their backbones; the former is derived from VSV, whereas for the latter, the backbone comes from lentiviruses such as $\mathrm{HIV}^{36}$ or murine leukemia virus ${ }^{38}$. Compared with VSV-based SARS-CoV-2 pseudotyped viruses, lentivirus-based SARS-CoV-2 pseudotyped viruses have a relatively low pseudoviral titer, for which the relative light unit (RLU) is $\sim 10^{6}$, and can be applied only to hACE2 overexpressed cell lines ${ }^{36,37}$. hACE2 has been identified as the receptor for SARS-CoV-2 to enter host cells $^{24,39}$. It is expected that overexpressed receptors on the host cell surface can enhance the efficiency of infectivity for SARS-CoV-2 pseudotyped virus. The low-titer lentivirus-based SARS-CoV-2 pseudotyped viruses have to employ the hACE2 overexpressed cell lines to yield robust data. The RLU value of SARS-CoV-2 pseudotyped virus based on VSV can reach $10^{8}$, which is 100 times as high as that of the lentivirus system, which means the signal-to-noise ratio of the assay becomes higher and makes the precision and repeatability better. It can be used in cell lines such as Huh-7 or Vero, which are more accessible. In addition, a SARS-CoV-2 neutralization test based on lentivirusproduced pseudovirus will take $48-60 \mathrm{~h}$ for incubation after infection, whereas VSV-based pseudotyped virus neutralization assays take just $20-28 \mathrm{~h}$ for incubation. VSV replicates in the cytoplasm $^{40,41}$. Conversely, the lentivirus must be reverse-transcribed during replication, which involves transportation of genetic materials between the nucleus and cytoplasm ${ }^{42,43}$. Thus, lentiviral replication takes longer than for VSV. The shorter incubation time may be attributed to the shorter replication time for VSV. This can save time and improve the detection efficiency.

\section{Experimental design}

\section{Testing for contamination}

To check for potential contamination of the SARS-CoV-2 pseudotyped virus stock with residual $\mathrm{G}^{*} \Delta \mathrm{G}-\mathrm{VSV}$, the SARS-CoV-2 pseudotyped virus stock should be tested by using a VSV G-specific antibody sample when the pseudotyped virus is first used. In our laboratory, the VSV G-specific antibody was generated by immunizing Balb/c mice with VSV G-expressing plasmid at an amount of $20 \mu \mathrm{g} /$ mouse three times at intervals of 2 weeks. 2 weeks after the final inoculation, blood samples were collected from anesthetized mice by retro-orbital vein bleed, incubated for $1 \mathrm{~h}$ at $37^{\circ} \mathrm{C}$ and then centrifuged $\left(2,000 \mathrm{~g}\right.$ at room temperature $\left(22-28^{\circ} \mathrm{C}\right)$ for $\left.10 \mathrm{~min}\right)$ to recover the serum. So far, residual $\mathrm{G}^{*} \Delta \mathrm{G}-\mathrm{VSV}$ has not been detected in the SARS-CoV-2 and other pseudotyped virus stocks in our laboratory ${ }^{23}$. Thus, we suggest that this procedure could be omitted if strictly following this protocol.

\section{Validation and controls}

The amount of pseudotyped virus added in the neutralization assay will affect the precision and repeatability of the approach. The amount of virus should be kept within a relatively fixed range. According to the optimization results of this assay previously reported, the amount of virus added was $650 \mathrm{TCID}_{50}$ per well $\left(325-1,300 \mathrm{TCID}_{50} \text { per well }\right)^{23}$. To validate the test operation process, the coefficient of variance (CV) of replicates should be controlled within $30 \%$ across six wells. The CV of the duplicate wells for samples is also required to be $\leq 30 \%$. In addition to this CV control of each test plate, we also set up negative (NC) and positive (PC) internal controls for each assay. The NC is human sera collected before the outbreak of COVID-19. The PC serum was from convalescent 
patients with COVID-19. The NC and PC samples should be tested along with the testing samples in each run. The $\mathrm{EC}_{50}$ value for $\mathrm{NC}$ and $\mathrm{PC}$ samples used in our laboratory was tested for 30 independent runs. All NC samples were negative at 30-fold dilution. The $\mathrm{EC}_{50}$ for PC samples was calculated, and its range of the mean \pm 2 s.d. was used as the criterion for the PC. At present, the $\mathrm{EC}_{50}$ ranges of quality controls used in our laboratory are $<30$ for the NC and 978-2,376 for the PC. Because of restrictions on the export of human samples, the internal control cannot be provided to laboratories that want to establish the method, especially foreign laboratories. It is suggested that laboratories planning to establish the SARS-CoV-2 pseudotyped virus neutralization assay should develop their own internal quality controls to monitor the method.

The validity of each sample, each plate and each run is evaluated against a set of pre-specified acceptance criteria. The percent $\mathrm{CV}(\% \mathrm{CV})$ for duplicate wells checks the validity of individual sample. The $\% \mathrm{CV}$ of VC wells, and the ratio of VC to CC checks the validity of the plate. The $\mathrm{EC}_{50}$ criterion of the NC and the PC validates the test run. The pass/fail criteria used in this assay are listed below:

1 The $\% \mathrm{CV}$ for duplicate wells is $\leq 30 \%$ for sample dilutions.

2 The \%CV of the RLU in the VC wells is $\leq 30 \%$.

3 The average RLU of VC wells is $\geq 1,000$ times the average RLU of CC wells.

4 The $\mathrm{EC}_{50}$ value of the negative sample derived from human serum is $<30$ (ref. ${ }^{23}$ ).

5 The $\mathrm{EC}_{50}$ value of the positive control is $978-2,376$.

If the first criterion is not met, then the result for this sample is deemed invalid. The test for this sample should be re-tested. If the second or third criteria are not met, then the results for this plate are deemed invalid and should be re-tested. If the fourth or fifth criteria are not met, then the results for this run are all deemed invalid and should be re-tested.

\section{Exportation and calculation of results}

To calculate the concentration of neutralizing antibody or inhibitor in the tested samples, the RLU values read by the luminometer should be exported as a Microsoft Excel file. Just copy the data of the wells B2-G11 of the exported Excel file and paste them into the corresponding cells in the 'Neutralization_SARS-CoV-2' macro (Supplementary Method 2 and Box 1), and the EC 50 value of each sample will be calculated automatically. In this procedure, the infection inhibition rates of each dilution of the sample are calculated according to the RLU values as follows: inhibition rate $=$ [1 - (average RLU of sample - average RLU of CC)/(average RLU of VC - average RLU of CC)] $\times$ $100 \%$. On the basis of the results of inhibition rate, the $\mathrm{EC}_{50}$ of each sample is calculated by the ReedMuench method. All of these procedures have been incorporated into the 'Neutralization_SARSCoV-2' macro.

\section{Materials}

\section{Biological materials}

- Cell line used for pseudotyped virus generation: HEK293T cells (American Type Culture Collection, cat. no. CRL-3216; RRID: CVCL_0063)

- Cell line used for pseudotyped virus infection: Huh-7 cells (JCRB, cat. no. JCRB0403; RRID: CVCL_ 0336) ! CAUTION The cell lines should be regularly checked to ensure that they are authentic and are not infected with mycoplasma.

- pcDNA3.1.S2 recombinant plasmid (GenBank: MT613044), which was constructed by inserting the codon-optimized $S$ gene of SARS-CoV-2 (GenBank: MN908947) into pcDNA3.1 plasmid by using $\mathrm{BamH} \mathrm{I}$ and $\mathrm{Xba}$ I restriction sites ${ }^{23}$. It can be shared upon request, or you can get the plasmid through Addgene (Addgene ID: 149457). The plasmid map can be found in Supplementary Fig. 1

- pcDNA3.1.VSVG recombinant plasmid (GenBank: MT613045), which was constructed by inserting codon-optimized VSV G gene (Genbank: M27165) into pcDNA3.1. It can be shared upon request, or you can get the plasmid through Addgene (Addgene ID: 158528). The plasmid map can be found in Supplementary Fig. 2

- $\mathrm{G}^{*} \Delta \mathrm{G}-\mathrm{VSV}$, a VSV G pseudotyped virus, in which the $G$ gene of the VSV genome was replaced by Fluc reporter genes. It was kindly provided by M. A. Whitt ${ }^{17}$. It can be obtained from Kerafast (EH1020PM; https://www.kerafast.com/productgroup/172/pseudotyped-g-luciferase-gg-luciferase-rvsv)

- Animal serum samples. The mice serum samples in this protocol were collected from Balb/c mice (females, $\sim 15 \mathrm{~g}$ in weight) inoculated three times with $20 \mu \mathrm{g}$ of plasmid pcDNA3.1.S2 followed by electroporation at an interval of 2 weeks $^{22} .2$ weeks after the final inoculation, blood samples were 
collected from anesthetized mice by retroorbital vein bleed, incubated for $1 \mathrm{~h}$ at $37{ }^{\circ} \mathrm{C}$ and then centrifuged $(2,000 \mathrm{~g}$ at room temperature for $10 \mathrm{~min})$ to recover the serum. ! CAUTION All animal experiments have to be performed in accordance with the ethical guidelines of the institution. All the animal experiments in this protocol were carried out according to the protocols approved by the Institutional Animal Care and Use Committee of the National Institutes for Food and Drug Control.

- Human serum samples. The SARS-CoV-2 negative and positive serum samples used in this protocol were kindly provided by Qiang Gao from Sinovac Biotech. The test samples of convalescent sera (CS3 and CS4) were provided by Xiaoming Yang from China National Biotec Group. ! CAUTION All experiments involving human samples must be approved by the ethics committee. Informed consent has to be obtained from the involved individuals.

\section{Reagents}

- Qiagen plasmid plus maxi kit (Qiagen, cat. no. 12963)

- DMEM (high glucose; Hyclone, cat. no. SH30243.01)

- Opti-MEM I reduced serum medium (Gibco, cat. no. 31985088)

- FBS (Pansera ES; PAN-Biotech GmbH, cat. no. ST30-2602)

- PBS (Hyclone, cat. no. SH30256.01)

- Lipofectamine 3000 transfection reagent (Thermo Fisher Scientific, cat. no. L3000015) ! CAUTION This reagent is toxic. Avoid contact, ingestion and inhalation. Wear gloves and handle with care.

- $0.25 \%$ trypsin-EDTA (Gibco, cat. no. 25200056)

- HEPES (Genom, cat. no. GNM-11344; or Gibco, cat. no. 15630080)

- Penicillin-streptomycin solution (Genom, cat. no. GNM15140; or Gibco, cat. no. 15140163) ! CAUTION This reagent is hazardous. Avoid contact, ingestion and inhalation. Wear gloves and handle with care. Those who are allergic to penicillin should pay special attention to it.

- Britelite plus reporter gene assay system (PerkinElmer, cat. no. 6066769)

- DH5a chemically competent cells (Zomanbio, cat. no. ZC101; or Invitrogen, cat. no. 12034013)

- Ampicillin sodium salt (VWR, cat. no. 0339-100G) !CAUTION This reagent is hazardous. Avoid contact, ingestion and inhalation. Wear gloves and handle with care. Those who are allergic to penicillin should pay special attention to it.

- Tryptone (Oxoid, cat. no. LP0042)

- Yeast extract (Oxoid, cat. no. LP0021)

- Agar powder (Meitan, cat. no. 11Y03)

\section{Equipment}

- Bacterial coating rod (Coolwind, cat. no. QFC01-LS0015D)

- Cell culture tube (BD Falcon, cat. no. 352006)

- Triangle bottle (Nalgene, cat. no. 4112-0250)

- Acrodisc syringe filters with supor membrane (Sterile $0.45 \mu \mathrm{m}, 25 \mathrm{~mm}$; Pall, cat. no. 4614)

- Serological pipettes: 5, 10 and $25 \mathrm{ml}$ (Costar, cat. nos. 4487, 4488 and 4489)

- Cell culture plate (96-well clear polystyrene microplates; Corning, cat. no. 3599)

- Cell culture flask (75 $\mathrm{cm}^{2}$; Corning, cat. no. 430641)

- Centrifuge tubes: 15 and $50 \mathrm{ml}$ (Corning, cat. nos. 430790 and 430828)

- Microtubes: 1.5 and $2 \mathrm{ml}$ (Axygen, cat. no. MCT-150-C and MCT-200-C)

- Chemiluminescence detection plates (96-well; Xiamen Labware, cat. no. 3599; or PerkinElmer, cat. no. 6005290)

- QIAvac24 Plus (Qiagen, model no. 19413)

- NanoDrop One microvolume UV-visible spectrophotometer (Thermo Scientific, model no. ND-ONE)

- Inverted microscope (Zeiss, model no. Primovert)

- Cell counter (Nexcelom, model no. Cellometer Auto T4)

- Cell culture incubator (5\% (vol/vol) $\mathrm{CO}_{2}$ humidified, $37^{\circ} \mathrm{C}$; NuAire, model no. NU-5810E)

- Electroporation instrument (Teresa, model no. Gene Delivery Device A)

- Luminometer (PerkinElmer, model no. HH34000000)

\section{Reagent setup}

- LB medium. Prepare by adding $10 \mathrm{~g}$ of tryptone, $5 \mathrm{~g}$ of yeast extract, $10 \mathrm{~g}$ of $\mathrm{NaCl}$ and deionized water to 1 liter. Divide into aliquots and distribute to $250-\mathrm{ml}$ flasks ( $100 \mathrm{ml}$ per flask). Seal with seal film and autoclave. Store at $2-8{ }^{\circ} \mathrm{C}$ for $\leq 2$ weeks before use. 
- Solid LB medium. Prepare by adding $10 \mathrm{~g}$ of tryptone, $5 \mathrm{~g}$ of yeast extract, $10 \mathrm{~g}$ of $\mathrm{NaCl}, 12 \mathrm{~g}$ of agar and deionized water to 1 liter. Divide into aliquots and distribute to $1,000-\mathrm{ml}$ flasks (500 $\mathrm{ml}$ per flask). Seal with seal film and autoclave. When the temperature of the medium decreases to $70-80{ }^{\circ} \mathrm{C}$, divide into aliquots and distribute to $100-\mathrm{mm}$ cell culture plates $(20 \mathrm{ml}$ per plate). When the medium has solidified completely, transfer the plates to $2-8{ }^{\circ} \mathrm{C}$. Store at $2-8{ }^{\circ} \mathrm{C}$ for $\leq 2$ weeks.

- Complete DMEM. Prepare by adding 10\% (vol/vol) FBS, 2\% (vol/vol) HEPES and 1\% (vol/vol) penicillin-streptomycin to DMEM. Stored at $2-8{ }^{\circ} \mathrm{C}$ for $\leq 7 \mathrm{~d}$ before use.

- Cell wash solution. Prepare by adding $1 \mathrm{ml}$ of FBS to $99 \mathrm{ml}$ of PBS to make PBS solution with $1 \%$ (vol/vol) FBS. Store at $2-8{ }^{\circ} \mathrm{C}$ for $\leq 7 \mathrm{~d}$ before use.

\section{Procedure}

pcDNA3.1.VSVG and pcDNA3.1.S2 plasmid stock preparation Timing $3 \mathrm{~d}$

1 Transfer 1 vial of DH5a competent bacteria $(50 \mu \mathrm{l}$ per vial) into an ice bath box. When the competent bacteria begin to thaw, add $1 \mu \mathrm{l}$ of plasmid (pcDNA3.1.VSVG or pcDNA3.1.S2) into it and place it back in ice for $30 \mathrm{~min}$.

$230 \mathrm{~min}$ later, put the competent bacteria into a $42{ }^{\circ} \mathrm{C}$ water bath for $45-60 \mathrm{~s}$. Then, place them back into the ice box for $2 \mathrm{~min}$. Next, add $500 \mu \mathrm{l}$ of LB medium into the transformed competent bacteria and place it in a $37^{\circ} \mathrm{C}$ shaker at a speed of $120 \mathrm{rpm}$ for $1 \mathrm{~h}$.

3 After incubation in the shaker, add $50 \mu \mathrm{l}$ of the bacteria onto a bacterial culture plate (solid LB medium with $100 \mu \mathrm{g} / \mathrm{ml}$ ampicillin) and spread it evenly by using a bacterial coating rod. Next, place the plate into a $37^{\circ} \mathrm{C}$ incubator overnight (14-16 h).

4 On the next day, pick a single colony of the bacteria by using a sterile $10-\mu$ pipette tip and put it into a cell culture tube with $5 \mathrm{ml}$ of LB medium (containing $100 \mu \mathrm{g} / \mathrm{ml}$ ampicillin). Then, put the tube back into a $37{ }^{\circ} \mathrm{C}$ shaker at a speed of $220 \mathrm{rpm}$ overnight (14-16 h).

5 After the overnight incubation, transfer $100 \mu$ of the cultured bacteria into a 250 -ml triangle bottle with $100 \mathrm{ml}$ of LB medium (containing $100 \mu \mathrm{g} / \mathrm{ml}$ ampicillin). Then, put it into a $37^{\circ} \mathrm{C}$ shaker at a speed of $220 \mathrm{rpm}$ overnight (14-16 h).

6 Collect the bacteria by centrifuging at a speed of $6,000 \mathrm{~g}$ for $15 \mathrm{~min}$ at $4{ }^{\circ} \mathrm{C}$.

7 Discard the supernatant and resuspend the pelleted bacteria by using $8 \mathrm{ml}$ of Buffer P1. Then, add $8 \mathrm{ml}$ of Buffer P2, mix gently four to six times by inverting and incubate at room temperature for $3 \mathrm{~min}$. Next, add $8 \mathrm{ml}$ of Buffer S3 and mix immediately by inverting four to six times. Transfer the solution into a QIAfilter cartridge and incubate at room temperature for $10 \mathrm{~min}$.

8 During incubation, place the spin columns into the QIAvac 24 Plus. Insert tube extenders into each column. Then, push the plunger into the cartridge and filter the cell lysate into 50-ml centrifuge tubes. Next, add $5 \mathrm{ml}$ of Buffer BB and invert it four to six times.

9 Transfer the lysate solution to Qiagen plasmid plus spin columns placed on the QIAvac24 Plus. Apply a vacuum of $\sim 300$ mbar until all the solution has been drawn through the columns. Then, switch off the vacuum. It takes $\sim 5-10 \mathrm{~min}$.

10 Add $700 \mu \mathrm{l}$ of Buffer ETR into the spin column and apply vacuum until the filter is dried.

11 Place the spin columns into 2-ml tubes and centrifuge at $10,000 \mathrm{~g}$ for $1 \mathrm{~min}$ at room temperature to remove the residual buffer.

12 Place the spin columns into clean 2-ml tubes, add $400 \mu \mathrm{l}$ of Buffer EB to the spin columns and let them stand for $2 \mathrm{~min}$. Then, centrifuge for $1 \mathrm{~min}$ to collect the purified plasmids.

13 Determine the concentration of plasmid by using a spectrophotometer. If $\mathrm{OD}_{260} / \mathrm{OD}_{280}=1.8-2.0$, $\mathrm{A}_{260}>0.1$ and $\mathrm{A}_{320} \leq 0.01$, then the plasmid meets the quality criteria for transfection.

14 Make $50-\mu \mathrm{g}$ aliquots of the plasmid in a sterile $2-\mathrm{ml}$ tube and store at $-80{ }^{\circ} \mathrm{C}$ until use.

DAUSE POINT The plasmids can be stored at $-80{ }^{\circ} \mathrm{C}$ for $\leq 1$ year before use.

\section{G^ $\Delta$ G-VSV and SARS-CoV-2 pseudotyped virus stock preparation Timing $3 \mathrm{~d}$}

$\triangle$ CRITICAL G* ${ }^{*}$ G-VSV pseudotyped virus is needed for producing SARS-CoV-2 pseudotyped virus. $\mathrm{G}^{*} \Delta \mathrm{G}-\mathrm{VSV}$ can initially be obtained from Kerafast (EH1020-PM). However, it is only an aliquot with $300 \mu \mathrm{l}$ of working stock, which is not enough to generate the SARS-CoV-2 pseudotyped virus. Thus, it is necessary to generate additional working stocks by amplifying $\mathrm{G}^{*} \Delta \mathrm{G}-\mathrm{VSV}$ by using the steps in this 
section (and plasmid pcDNA3.1.VSVG in Step 18) before production of SARS-CoV-2 pseudotyped virus, also following this section (and using plasmid pcDNA3.1.S2 in Step 18).

\section{Cell preparation for pseudotyped virus production}

15 We maintain the 293T cells in complete DMEM medium and prepare cells for pseudotyped virus production as described below. First, when the $293 \mathrm{~T}$ cells grow to a $70-90 \%$ confluence in a T75 flask, carefully discard the supernatant culture medium of the flask. Then, add $10 \mathrm{ml}$ of $37^{\circ} \mathrm{C}$ pre-warmed PBS to the flask to clean the cell surface. Next, discard the cleaning solution and add $3 \mathrm{ml}$ of $0.25 \%$ trypsin-EDTA to the flask to cover the cells. Rest at room temperature for $1 \mathrm{~min}$ and discard trypsin by pipetting. Transfer the cells to a $37^{\circ} \mathrm{C}, 5 \%$ (vol $/ \mathrm{vol}$ ) $\mathrm{CO}_{2}$ incubator and incubate for $5 \mathrm{~min}$. After that, add $10 \mathrm{ml}$ of DMEM complete medium preheated at $37^{\circ} \mathrm{C}$ to the cell culture flask and resuspend the cells thoroughly by repeated pipetting with a serological pipette to make sure the cells are dispersed into a single cell suspension.

\section{? TROUBLESHOOTING}

16 Count the cells by using a cell counter and adjust the cell concentration to $5-7 \times 10^{5}$ cells $/ \mathrm{ml}$ with DMEM complete medium. Then, transfer $15 \mathrm{ml}$ into a T75 cell flask and place it in a $5 \%(\mathrm{vol} / \mathrm{vol})$ $\mathrm{CO}_{2}$ cell incubator at $37^{\circ} \mathrm{C}$ overnight.

\section{Transfection and infection}

17 Check the cell density before cell transfection. The cell density should reach $70-90 \%$ confluence after overnight incubation.

$\triangle$ CRITICAL STEP If the cell density has not reached the expected confluence, replace the culture medium and lengthen the incubation time for another 4-6 h.

18 Add $0.75 \mathrm{ml}$ of opti-MEM into a new 2-ml microtube (labeled 'tube A'). Then, add $30 \mu \mathrm{g}$ of plasmid pcDNA3.1.VSVG (or plasmid pcDNA3.1.S2) into tube A. Next, add $30 \mu \mathrm{l}$ of P3000 (a component in the Lipofectamine 3000 kit) into tube A and mix it by using a pipette. Rest it at room temperature for $5 \mathrm{~min}$.

19 Transfer $0.75 \mathrm{ml}$ of opti-MEM into another 2-ml microtube (marked as 'tube B') and add $30 \mu \mathrm{l}$ of Lipofectamine 3000 into it. Mix the solution gently and place it at room temperature for $5 \mathrm{~min}$.

20 After a 5-min incubation, add the solution of tube B to tube A drop by drop. Invert tube A four to six times gently to mix the mixture completely, and rest it at room temperature for $15-20 \mathrm{~min}$.

$\triangle$ CRITICAL STEP Make sure that the mixing is gentle and complete, which will influence the efficiency of transfection.

21 During the room temperature incubation (Step 20), dilute G* $\Delta$ G-VSV (VSV G pseudotyped virus) to $7.0 \times 10^{4} \mathrm{TCID}_{50} / \mathrm{ml}$. Discard the culture medium of $293 \mathrm{~T}$ cells from Step 17 and then add $15 \mathrm{ml}$ of the diluted $\mathrm{G}^{*} \Delta \mathrm{G}-\mathrm{VSV}$ solution into the T75 flask.

22 After the incubation in Step 20 comes to an end, pipette all the solution in tube A into the supernatant of the $293 \mathrm{~T}$ cell flask and mix it by slowly pipetting four to six times. Place it in a $5 \%(\mathrm{vol} / \mathrm{vol}) \mathrm{CO}_{2}$ incubator at $37^{\circ} \mathrm{C}$ for $6-8 \mathrm{~h}$ or overnight.

23 After the incubation, aspirate the culture medium and wash the cells by using $10-15 \mathrm{ml}$ of cell wash solution (PBS containing 1\% (vol/vol) FBS) to rinse the cells gently and thoroughly. Repeat this step three times.

$\triangle$ CRITICAL STEP This wash step should be performed carefully and gently to avoid detaching the cells. Detached cells will yield lower-titer or even no pseudotyped viruses.

? TROUBLESHOOTING

24 Add $15 \mathrm{ml}$ of fresh complete DMEM to the flask and place it in a $5 \%$ (vol $/ \mathrm{vol}$ ) $\mathrm{CO}_{2}$ incubator at $37^{\circ} \mathrm{C}$ for $24 \mathrm{~h}$.

25 Collect the cell supernatant (supernatant A) into a 50-ml centrifuge tube by pipetting and place it in a $4{ }^{\circ} \mathrm{C}$ refrigerator. Then, add $15 \mathrm{ml}$ of fresh complete DMEM into the 293T cells and incubate for another $24 \mathrm{~h}$.

26 After the second incubation, harvest the supernatant (supernatant B) and mix it with supernatant A by pipetting. Centrifuge the mixture at $1,000 \mathrm{~g}$ for $10 \mathrm{~min}$ at room temperature. Filter by using a $0.45-\mu \mathrm{m}$ filter. Distribute $1-\mathrm{ml}$ aliquots of the mixture into $2-\mathrm{ml}$ microtubes and store them at $-80^{\circ} \mathrm{C}$.

PAUSE POINT The harvested pseudotyped virus can be stored at $-80^{\circ} \mathrm{C}$ for $\leq 1$ year according to the conditions used for other pseudotyped viruses ${ }^{17,22}$. 
Titration of the SARS-CoV-2 pseudotyped virus Timing $\mathbf{2 d}$

27 Take the pseudotyped virus from the $-80{ }^{\circ} \mathrm{C}$ refrigerator and thaw it in a room temperature water bath.

28 Use a 96-well flat-bottom culture plate to titrate the pseudotyped virus. Seal the outmost wells with $250 \mu$ of sterilized water per well to avoid the effect caused by evaporation of the edge-well culture medium (Fig. 2a).

29 Place $135 \mu \mathrm{l}$ of complete DMEM in wells B2-G2. Add $100 \mu \mathrm{l}$ of complete DMEM into the remaining wells (B3-G11). Add $15 \mu \mathrm{l}$ of pseudotyped virus per well to wells B2-G2 to make an initial dilution of 1:10.

30 Start the serial dilution by transferring $50 \mu$ of solution from wells B2-G2 to wells B3-G3 with a multi-channel pipette, mix six to eight times and then transfer $50 \mu \mathrm{l}$ from wells B3-G3 to wells B4-G4. Repeat the transfer and dilution of samples through to wells B10-G10. After the final mixing, aspirate $50 \mu \mathrm{l}$ of solution from each well in column 10 and discard it. The dilution step does not involve column 11 (B11-G11), which will be used as the CC.

31 Prepare Huh-7 cells as described in Step 15. Then, adjust the cell concentration to $2 \times 10^{5}$ cells $/ \mathrm{ml}$ with DMEM complete medium and add $100 \mu \mathrm{l}$ of cell suspension into all of the 60 inner wells (B2-G11).

32 Place the titration plate in the $5 \%$ (vol/ $/ \mathrm{vol}) \mathrm{CO}_{2}, 37^{\circ} \mathrm{C}$ incubator for $20-28 \mathrm{~h}$.

33 After the incubation, thaw the required volume of the Britelite plus reagent before use in an ambient temperature water bath.

$\triangle$ CRITICAL STEP The temperature of Britelite plus reagent can influence the readout of the sample. Place the reagent in a water bath not less than 30 min before use.

34 Remove and discard $100 \mu \mathrm{l}$ of supernatant from each well, leaving $100 \mu \mathrm{l}$ of liquid in each well.

35 Disperse $100 \mu \mathrm{l}$ of the Britelite plus reagent into each well.

36 Incubate in darkness at room temperature for $2 \mathrm{~min}$ to allow complete cell lysis. Mix by pipettor action (six to eight times) and transfer $150 \mu \mathrm{l}$ to a corresponding 96-well chemiluminescence detection plate. $\triangle$ CRITICAL STEP Note that the transparent cell culture plate is not suitable for chemiluminescence detection. The cell lysates should be transferred to specific plates for detection.

37 Read the RLU of the plate after the 2-min incubation in the luminescence meter.

38 Take 10 times of the average RLU of the CC wells (B11-G11) as the cutoff value. Wells with an RLU equal to or higher than the cutoff value are considered positive. On the basis of the positive and negative rate in each dilution, calculate the $\mathrm{TCID}_{50}$ according to the Reed-Muench method by using the 'TCID50_SARS-CoV-2' macro (Supplementary Method 1 and Box 1). Figure 3 shows how to use the macro file to calculate the $\mathrm{TCID}_{50}$ for pseudotyped virus titration.

? TROUBLESHOOTING

\section{Pseudotyped virus neutralization assay $\bigcirc$ Timing $1 \mathrm{~d}$}

39 Sample preparation. Serum samples from animals or humans should be inactivated in a water bath at $56^{\circ} \mathrm{C}$ for $30 \mathrm{~min}$.

!CAUTION All animal experiments have to be carried out in accordance with the ethical guidelines of the institution. All experiments involving human specimens should be approved by the ethics committee. Informed consent must be obtained from the involved individuals.

\section{? TROUBLESHOOTING}

40 Prepare a culture plate and seal the outmost wells as in Step 28.

41 Place $150 \mu$ l of complete DMEM medium per wellin column 2 (B2-G2), which is used as the CC (Fig. 2b). Add $100 \mu$ l of complete DMEM into each well of column 3 (B3-G3), which is designated as the VC.

42 Dispense $142.5 \mu \mathrm{l}$ of complete DMEM per well in the remaining wells of row B (B4-B11), which is the initial dilution row. Add $100 \mu \mathrm{l}$ of complete DMEM per well to the remaining wells (C4-G11).

43 Add $7.5 \mu$ of the test sample in duplicate to row B (B4-B11) in the following order: sample 1, wells B4-B5; sample 2, wells B6-B7; sample 3, wells B8-B9; sample 4, wells B10-B11.

$\triangle$ CRITICAL STEP After addition of the sample, rinse the tips by using the medium in the corresponding wells to avoid leaving residual samples on the tip walls. $7.5 \mu \mathrm{l}$ of sample $+142.5 \mu \mathrm{l}$ of medium yields a sample dilution of 1:20.

$\triangle$ CRITICAL STEP A positive and a negative control should be included in at least one plate in each run of the assay. The positive and negative controls are treated the same as the test samples.

44 Mix the samples in row B by pipetting with a multi-channel pipette and transfer $50 \mu \mathrm{l}$ from each well in row B to row $C$. Repeat the mixing and transfer through row $G$ (they are threefold serial 
dilutions). After final transfer and mixing, discard $50 \mu$ of liquid from the wells in the final row of columns 4-11 (wells G4-G11).

45 Thaw the required amount of pseudotyped virus in an ambient temperature bath. Dilute the SARS-CoV-2 pseudotyped virus to $1.3 \times 10^{4} \mathrm{TCID}_{50} / \mathrm{ml}$ in complete DMEM. Dispense $50 \mu \mathrm{l}$ of the diluted pseudotyped virus into each well in columns 3-11. Then, cover the plates and incubate in a $5 \%$ (vol/vol) $\mathrm{CO}_{2}, 37^{\circ} \mathrm{C}$ incubator for $\sim 60 \mathrm{~min}(45-90 \mathrm{~min}$ ).

$\triangle$ CRITICAL STEP Note that no pseudotyped viruses are added in the CC wells. Pseudotyped viruses are dispensed into $\mathrm{VC}$, negative control and positive control wells in the same way as the test sample wells.

$\triangle$ CRITICAL STEP After addition of the pseudotyped virus, the sample is diluted another 1.5-fold, which makes the initial dilution 1:30 followed by five serial threefold dilutions. The final dilution of the sample will be 1:7,290.

46 After a 30-min incubation, start to prepare the Huh-7 cells as in Step 31 and when the incubation comes to an end, add cells as in Step 31 and place the titration plate in the $5 \%$ (vol/vol) $\mathrm{CO}_{2}, 37^{\circ} \mathrm{C}$ incubator for $20-28 \mathrm{~h}$.

47 After the incubation, repeat Steps 33-37 (removing $150 \mu \mathrm{l}$ of supernatant from each well in Step 34).

48 Export the raw data as an Excel file from the luminometer and paste the raw data into the Excel 'Neutralization_SARS-CoV-2' macro (Supplementary Method 2 and Box 1) to get the titer for each sample.

$\triangle$ CRITICAL STEP Figure 3 shows how to use the macro file to calculate the neutralization titers for serum, antibody or fusion inhibitors by changing the wells of dilution factor and start dilution.

? TROUBLESHOOTING

\section{Troubleshooting}

Troubleshooting advice can be found in Table 1.

Table 1 | Troubleshooting table

\begin{tabular}{lll} 
Step & Problem & Possible reason \\
\hline 15 & The cells are lumpy after plating & Incomplete digestion \\
& & \\
$23 \quad \begin{array}{l}\text { Cells are detached from the surface } \\
\text { of the culture flasks }\end{array}$ & $\begin{array}{l}\text { When washing or adding culture } \\
\text { medium, the liquid is added directly } \\
\text { to the cells }\end{array}$
\end{tabular}

38 The titers of pseudotyped virus are The transfection efficiency was low too low

39 The sample is not clear

48 The RLUs for the VC are not exactly the same in different runs

$\% \mathrm{CV}$ between duplicates is $>30 \%$
The serum/plasma sample contains blood lipids or fiber precipitation

Even diluted according to the same $\mathrm{TCID}_{50}$, the RLU may not be exactly the same

Inaccuracy of sample addition or dilution

\section{Solution}

Before washing the cells by using PBS, the culture medium should be discarded completely. After cleaning with PBS, aspirate and discard the PBS completely. After discarding trypsin, the cell culture bottle should be placed in the incubator without disturbing the cells

Incubate strictly according to the protocol timeline to avoid a prolonged digestion period

When rinsing cells or adding culture medium, tilt the culture bottle to make the cellular side face up. Add the liquid to the acellular side. When the liquid flows to the bottom of the flask, turn it gently to make the liquid infiltrate the cell surface. This method should be applied to all cell-processing operations

Lipofectamine 3000 should be fully mixed with the plasmid in Step 19. The liquids in tubes A and B should be fully mixed in Step 20 so that the liposome can encapsulate the plasmid efficiently

After inactivation, serum or plasma samples should be centrifuged at $6,000 \mathrm{~g}$ for $10 \mathrm{~min}$. Then, the supernatant will be used for follow-up detection

Following the recommended dilution fold in the TCID 50 macro, it is acceptable as long as the VC/CC value is not $<1,000$ in the pseudotyped virus neutralization assay

When adding or diluting samples, observe the liquid level in the pipette tips to ensure an identical volume. It is recommended to use a multi-channel pipette to do the serial dilutions 
Step 1, plasmid addition for transformation: $3 \mathrm{~min}$, incubation in ice: $30 \mathrm{~min}$

Step 2, heat shock for transformation: $10 \mathrm{~min}$, incubation in shaker: $1 \mathrm{~h}$

Step 3, bacterial spreading: $5 \mathrm{~min}$, overnight incubation: $14-16 \mathrm{~h}$

Step 4, mono-colony picking: $5 \mathrm{~min}$, overnight incubation: $14-16 \mathrm{~h}$

Step 5, amplified culture of bacteria: $5 \mathrm{~min}$, overnight incubation: 14-16 h

Step 6, bacteria collection: $25 \mathrm{~min}$

Step 7, cell lysis and precipitation: $30 \mathrm{~min}$

Step 8, preparation of the spin column: $15 \mathrm{~min}$

Steps 9-12, washing and collecting the plasmid: $40 \mathrm{~min}$

Step 13, quantifying and determining the quality of the plasmid: $10 \mathrm{~min}$

Step 14, preparing aliquots of the plasmid: $15 \mathrm{~min}$

Steps 15 and 16, cell preparation for pseudotyped virus production: $45 \mathrm{~min}$, overnight incubation: 14-16 h

Steps 17-22, transfection and infection of $293 \mathrm{~T}$ cells: $1 \mathrm{~h}$, incubation: $6-8 \mathrm{~h}$

Steps 23 and 24, replacement of the transfection and infection solution with culture medium: $30 \mathrm{~min}$, incubation: $24 \mathrm{~h}$

Step 25, first harvest of the pseudotyped virus: $10 \mathrm{~min}$, incubation: $24 \mathrm{~h}$

Step 26, second harvest and aliquoting of the pseudotyped virus: $1 \mathrm{~h}$

Step 27, preparation of the pseudotyped virus for titration: $5 \mathrm{~min}$

Step 28, preparation of the culture plate for titration: $10 \mathrm{~min}$

Steps 29 and 30, pseudotyped virus dilution: $10 \mathrm{~min}$

Steps 31-33, preparation of cells for titration: $45 \mathrm{~min}$, incubation: $20-28 \mathrm{~h}$

Steps 34-37, luminescence detection: $30 \mathrm{~min}$

Step 38, titration calculation by using a macro: $5 \mathrm{~min}$

Step 39, sample preparation: 1 h $20 \mathrm{~min}$

Step 40, preparation of the culture plate for neutralization: $10 \mathrm{~min}$

Steps 41-44, serum or antibody sample dilution: $30 \mathrm{~min}$

Step 45, pseudotyped virus preparation and addition: $10 \mathrm{~min}$, incubation: $1 \mathrm{~h}$

Step 46, preparation and dispensing of cells: $45 \mathrm{~min}$, incubation: $20-28 \mathrm{~h}$

Step 47, luminescence detection: $30 \mathrm{~min}$

Step 48, calculation of the $\mathrm{EC}_{50}$ by using a macro: $5 \mathrm{~min}$

Following this protocol, high-titer SARS-CoV-2S pseudotyped viruses can be obtained. Even if diluted 10 times, the ratio of $\mathrm{VC} / \mathrm{CC}$ can reach $>1,000$. The high signal-to-noise ratio could ensure the precision of the assay. The titer of the pseudotyped virus and the expected dilution in the neutralization test can be calculated by using the Excel 'TCID50_SARS-CoV-2' macro (Supplementary Method 1, Box 1 and Fig. 4a). If the protocol is carried out appropriately to detect neutralizing antibodies in serum samples, a well-fitted inhibition curve can be observed automatically in the 'Neutralization_SARS-CoV-2' macro after importing the raw data (Fig. 4b). Four samples could be assayed in duplicate in each 96-well plate at the same time. The neutralizing antibody titer of the sample can be calculated by using the Excel 'Neutralization_SARS-CoV-2' macro (Supplementary Method 2 and Box 1). That is the dilution of a serum sample that inhibits $50 \%$ of viral infection. If the test sample is a monoclonal antibody or a fusion inhibitor with an assigned amount, the $\mathrm{EC}_{50}$ of the sample can be obtained (Fig. 4b).

\section{Reporting Summary}

Further information on the research design is available in the Nature Research Reporting Summary linked to this article.

\section{Data availability}

A sample dataset has been deposited in Figshare: https://figshare.com/articles/Raw_data_for_ Supplementary_methods_and_Figure_3_and_4/12486479/1. This dataset was used to generate Figs. 3 and 4 and is included as Source Data. Source data are provided with this paper. 

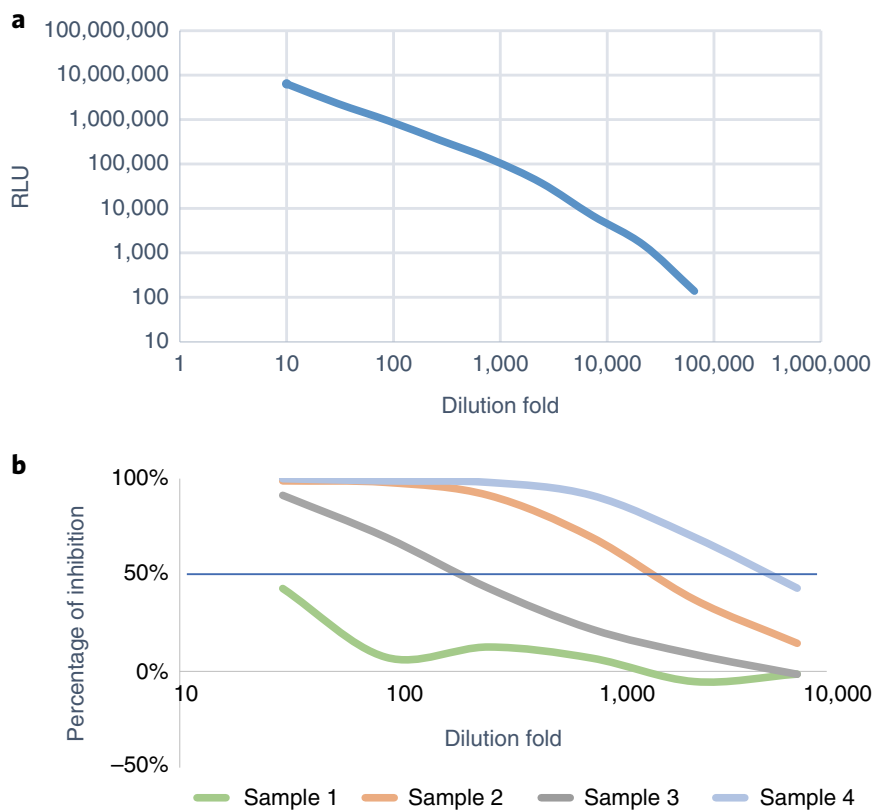

Fig. 4 | Titration (a) and neutralization (b) curves obtained by using the macro files (Supplementary Methods 1 and 2 and Box 1). a, Titration curve generated by using the TCID50_SARS-CoV-2 macro (Supplementary Method 1). The $x$-axis shows the dilution fold of pseudotyped viruses. The $y$-axis shows the RLU value of the luminescence meter readout. b, Neutralization curve generated by using the Neutralization_SARS-CoV-2 macro (Supplementary Method 2). Four samples can be assayed in the same 96-well plate. A four-parameter curve (S-shaped curve) can be obtained between the inhibition rate and log-transformed dilution fold, when the test sample can inhibit the infection of target cells by pseudotyped virus. It may be a partial S-shaped curve. Samples with low (sample 1), middle (sample 3), or high (samples 2 and 4) neutralization potency present posterior, middle or anterior segments of S curves, respectively, in this figure. When the neutralization curve crosses the $50 \%$ line, the $\mathrm{EC}_{50}$ for this sample can be calculated. The $\mathrm{EC}_{50}$ (thin blue line showing $50 \%$ inhibition) was calculated by using the Reed-Muench method automatically in the macro. The raw data have been deposited in Figshare (https://figshare.com/articles/Raw_data_for_Supplementary _ methods_and_Figure_3_and_4/12486479/1) and are available with this article as Source Data.

\section{References}

1. Chen, Y. et al. High SARS-CoV-2 antibody prevalence among healthcare workers exposed to COVID-19 patients. J. Infect. 81, 420-426 (2020).

2. Coronaviridae Study Group of the International Committee on Taxonomy of Viruses. The species Severe acute respiratory syndrome-related coronavirus: classifying $2019-\mathrm{nCoV}$ and naming it SARS-CoV-2. Nat. Microbiol. 5, 536-544 (2020).

3. Chen, Y., Liu, Q. \& Guo, D. Emerging coronaviruses: genome structure, replication, and pathogenesis. J. Med. Virol. 92, 418-423 (2020).

4. Li, C., Yang, Y. \& Ren, L. Genetic evolution analysis of 2019 novel coronavirus and coronavirus from other species. Infect. Genet. Evol. 82, 104285 (2020).

5. $\mathrm{Wu}, \mathrm{A}$. et al. Genome composition and divergence of the novel coronavirus (2019-nCoV) originating in China. Cell Host Microbe 27, 325-328 (2020).

6. Chan, J. F. et al. Genomic characterization of the 2019 novel human-pathogenic coronavirus isolated from a patient with atypical pneumonia after visiting Wuhan. Emerg. Microbes Infect. 9, 221-236 (2020).

7. $\mathrm{Du}, \mathrm{L}$. et al. The spike protein of SARS-CoV-a target for vaccine and therapeutic development. Nat. Rev. Microbiol. 7, 226-236 (2009).

8. Li, F. Structure, function, and evolution of coronavirus spike proteins. Annu. Rev. Virol. 3, 237-261 (2016).

9. Cho, H., Excler, J. L., Kim, J. H. \& Yoon, I. K. Development of Middle East Respiratory Syndrome Coronavirus vaccines-advances and challenges. Hum. Vaccin. Immunother. 14, 304-313 (2018).

10. Matsuyama, S. et al. Enhanced isolation of SARS-CoV-2 by TMPRSS2-expressing cells. Proc. Natl Acad. Sci. USA. 117, 7001-7003 (2020).

11. Zhu, Z. et al. Potent cross-reactive neutralization of SARS coronavirus isolates by human monoclonal antibodies. Proc. Natl Acad. Sci. USA. 104, 12123-12128 (2007).

12. Rockx, B. et al. Structural basis for potent cross-neutralizing human monoclonal antibody protection against lethal human and zoonotic severe acute respiratory syndrome coronavirus challenge. J. Virol. 82, 3220-3235 (2008).

13. Du, L. et al. MERS-CoV spike protein: a key target for antivirals. Expert Opin. Ther. Targets 21, 131-143 (2017). 
14. Zhou, Y. et al. Advances in MERS-CoV vaccines and therapeutics based on the receptor-binding domain. Viruses 11, 60 (2019).

15. Xia, S. et al. A pan-coronavirus fusion inhibitor targeting the HR1 domain of human coronavirus spike. Sci. $A d v .5$, eaav4580 (2019).

16. Yi, L. et al. Small molecules blocking the entry of severe acute respiratory syndrome coronavirus into host cells. J. Virol. 78, 11334-11339 (2004).

17. Whitt, M. A. Generation of VSV pseudotypes using recombinant DeltaG-VSV for studies on virus entry, identification of entry inhibitors, and immune responses to vaccines. J. Virol. Methods 169, 365-374 (2010).

18. Quinn, K. et al. Rho GTPases modulate entry of Ebola virus and vesicular stomatitis virus pseudotyped vectors. J. Virol. 83, 10176-10186 (2009).

19. Negrete, O. A. et al. EphrinB2 is the entry receptor for Nipah virus, an emergent deadly paramyxovirus. Nature 436, 401-405 (2005).

20. Lee, B. H. et al. A pseudotype vesicular stomatitis virus containing Hantaan virus envelope glycoproteins G1 and G2 as an alternative to hantavirus vaccine in mice. Vaccine 24, 2928-2934 (2006).

21. Moeschler, S. et al. Quantification of Lyssavirus-neutralizing antibodies using vesicular stomatitis virus pseudotype particles. Viruses 8, 254 (2016).

22. Ma, J. et al. In vitro and in vivo efficacy of a Rift Valley fever virus vaccine based on pseudovirus. Hum. Vaccin. Immunother. 15, 2286-2294 (2019).

23. Nie, J. et al. Establishment and validation of a pseudovirus neutralization assay for SARS-CoV-2. Emerg. Microbes Infect. 9, 680-686 (2020).

24. Zhou, P. et al. A pneumonia outbreak associated with a new coronavirus of probable bat origin. Nature 579, 270-273 (2020).

25. Matumoto, M. A note on some points of calculation method of LD50 by Reed and Muench. Jpn. J. Exp. Med. 20, 175-179 (1949).

26. Amanat, F. et al. A serological assay to detect SARS-CoV-2 seroconversion in humans. Nat. Med. 26, 1033-1036 (2020).

27. Ni, L. et al. Detection of SARS-CoV-2-specific humoral and cellular immunity in COVID-19 convalescent individuals. Immunity 52, 971-977.e3 (2020).

28. Tai, W. et al. Characterization of the receptor-binding domain (RBD) of 2019 novel coronavirus: implication for development of RBD protein as a viral attachment inhibitor and vaccine. Cell. Mol. Immunol. 17, 613-620 (2020).

29. Conte, C. et al. Vaccines against coronaviruses: the state of the art. Vaccines (Basel) 8, 309 (2020).

30. Ghaebi, M. et al. Vaccine development and therapeutic design for 2019-nCoV/SARS-CoV-2: challenges and chances. J. Cell Physiol. Forthcoming (2020).

31. Lv, Z. et al. Structural basis for neutralization of SARS-CoV-2 and SARS-CoV by a potent therapeutic antibody. Science Forthcoming (2020).

32. Ju, B. et al. Human neutralizing antibodies elicited by SARS-CoV-2 infection. Nature 584, 115-119 (2020).

33. Cao, Y. et al. Potent neutralizing antibodies against SARS-CoV-2 identified by high-throughput single-cell sequencing of convalescent patients' B cells. Cell 182, 73-84.e16 (2020).

34. Zhu, F. C. et al. Safety, tolerability, and immunogenicity of a recombinant adenovirus type- 5 vectored COVID-19 vaccine: a dose-escalation, open-label, non-randomised, first-in-human trial. Lancet 395, 1845-1854 (2020).

35. $\mathrm{Li}, \mathrm{Q}$. et al. The impact of mutations in SARS-CoV-2 spike on viral infectivity and antigenicity. Cell $\mathbf{1 8 2}$, 284-1294.e9 (2020).

36. $\mathrm{Ou}, \mathrm{X}$. et al. Characterization of spike glycoprotein of SARS-CoV-2 on virus entry and its immune crossreactivity with SARS-CoV. Nat. Commun. 11, 1620 (2020).

37. Crawford, K. H. D. et al. Protocol and reagents for pseudotyping lentiviral particles with SARS-CoV-2 spike protein for neutralization assays. Viruses 12, 513 (2020).

38. Pinto, D. et al. Structural and functional analysis of a potent sarbecovirus neutralizing antibody. Preprint at https://www.biorxiv.org/content/10.1101/2020.04.07.023903v3 (2020).

39. Hoffmann, M. et al. SARS-CoV-2 cell entry depends on ACE2 and TMPRSS2 and is blocked by a clinically proven protease inhibitor. Cell 181, 271-280.e8 (2020).

40. Lichty, B. D., Power, A. T., Stojdl, D. F. \& Bell, J. C. Vesicular stomatitis virus: re-inventing the bullet. Trends Mol. Med. 10, 210-216 (2004).

41. Munis, A. M., Bentley, E. M. \& Takeuchi, Y. A tool with many applications: vesicular stomatitis virus in research and medicine. Expert Opin. Biol. Ther. 20, 1187-1201 (2020).

42. Holmes, M., Zhang, F. \& Bieniasz, P. D. Single-cell and single-cycle analysis of HIV-1 replication. PLoS Pathog. 11, e1004961 (2015).

43. Ferguson, M. R., Rojo, D. R., von Lindern, J. J. \& O'Brien, W. A. HIV-1 replication cycle. Clin. Lab. Med. 22, 611-635 (2002).

\section{Acknowledgements}

This work was supported by National Science and Technology Major Projects of Drug Discovery (grant number 2018ZX09101001), National Science and Technology Major Projects of Infectious Disease (grant number 2017ZX10304402), Key Project of Public Safety Risk Prevention and Control and Emergency Technical Equipment (grant number 2020YFC0860500) and the Bill \& Melinda Gates Foundation (Investment ID INV-006379). 


\section{Author contributions}

J.N., C.F., W.H., M.X. and Y.W. wrote the paper and conceived and designed the experiments. J.N., Q.L., J.W., C.Z., H.H., H.L., L.Z., H.Q., L.N., J.L., M.W., Q.L., Q.S. and X.L. performed the experiments. J.N. and M.W. wrote the Excel macro files. All of the authors have read and approved the final manuscript.

\section{Competing interests}

The authors declare no competing interests.

\section{Additional information}

Supplementary information is available for this paper at https://doi.org/10.1038/s41596-020-0394-5.

Correspondence and requests for materials should be addressed to W.H., M.X. or Y.W.

Peer review information Nature Protocols thanks Shibo Jiang and the other, anonymous, reviewer(s) for their contribution to the peer review of this work.

Reprints and permissions information is available at www.nature.com/reprints.

Publisher's note Springer Nature remains neutral with regard to jurisdictional claims in published maps and institutional affiliations.

Received: 18 April 2020; Accepted: 14 August 2020;

Published online: 25 September 2020

\section{Related links}

Key references using this protocol

Nie, J. et al. Emerg. Microbes Infect. 9, 680-686 (2020): https://doi.org/10.1080/22221751.2020.1743767

Li, Q. et al. Cell (2020): https://doi.org/10.1016/j.cell.2020.07.012

Lv, Z. et al. Science 369, eabc5881 (2020): https://doi.org/10.1126/science.abc5881 


\section{Reporting Summary}

Nature Research wishes to improve the reproducibility of the work that we publish. This form provides structure for consistency and transparency in reporting. For further information on Nature Research policies, see Authors \& Referees and the Editorial Policy Checklist.

\section{Statistics}

For all statistical analyses, confirm that the following items are present in the figure legend, table legend, main text, or Methods section.

n/a Confirmed

\ $\square$ The exact sample size $(n)$ for each experimental group/condition, given as a discrete number and unit of measurement

$\square$ \A statement on whether measurements were taken from distinct samples or whether the same sample was measured repeatedly

The statistical test(s) used AND whether they are one- or two-sided

$\triangle$ Only common tests should be described solely by name; describe more complex techniques in the Methods section.

Х $\square$ A description of all covariates tested

Х $\square$ A description of any assumptions or corrections, such as tests of normality and adjustment for multiple comparisons

Х A full description of the statistical parameters including central tendency (e.g. means) or other basic estimates (e.g. regression coefficient)

X $\square$ AND variation (e.g. standard deviation) or associated estimates of uncertainty (e.g. confidence intervals)

$\triangle$ For null hypothesis testing, the test statistic (e.g. $F, t, r$ ) with confidence intervals, effect sizes, degrees of freedom and $P$ value noted

$\triangle \square$ Give P values as exact values whenever suitable.

Х $\square$ For Bayesian analysis, information on the choice of priors and Markov chain Monte Carlo settings

Х $\square$ For hierarchical and complex designs, identification of the appropriate level for tests and full reporting of outcomes

Х $\square$ Estimates of effect sizes (e.g. Cohen's $d$, Pearson's $r$ ), indicating how they were calculated

Our web collection on statistics for biologists contains articles on many of the points above.

\section{Software and code}

Policy information about availability of computer code

\section{Data collection Microsoft Excel}

Data analysis Microsoft Excel macro

For manuscripts utilizing custom algorithms or software that are central to the research but not yet described in published literature, software must be made available to editors/reviewers. We strongly encourage code deposition in a community repository (e.g. GitHub). See the Nature Research guidelines for submitting code \& software for further information.

\section{Data}

Policy information about availability of data

All manuscripts must include a data availability statement. This statement should provide the following information, where applicable:

- Accession codes, unique identifiers, or web links for publicly available datasets

- A list of figures that have associated raw data

- A description of any restrictions on data availability

\section{Field-specific reporting}

Please select the one below that is the best fit for your research. If you are not sure, read the appropriate sections before making your selection. $\bigotimes$ Life sciences $\quad \square$ Behavioural \& social sciences $\square$ Ecological, evolutionary \& environmental sciences 


\section{Life sciences study design}

All studies must disclose on these points even when the disclosure is negative.

Sample size
Data exclusions

Not applicable.

Replication

No data were excluded.

Randomization

Not applicable.

Blinding

Not applicable.

Not applicable.

\section{Reporting for specific materials, systems and methods}

We require information from authors about some types of materials, experimental systems and methods used in many studies. Here, indicate whether each material, system or method listed is relevant to your study. If you are not sure if a list item applies to your research, read the appropriate section before selecting a response.

\begin{tabular}{l|l} 
Materials \& experimental syste \\
\hline$\square / a$ & Involved in the study \\
$\square$ Antibodies \\
$\square$ Eukaryotic cell lines \\
$\square$ Palaeontology \\
$\square$ Clinical data
\end{tabular}

Methods

n/a Involved in the study

\ $\square$ ChIP-seq

Х Flow cytometry

$\bigotimes \square$ MRI-based neuroimaging

\section{Eukaryotic cell lines}

Policy information about cell lines

Cell line source(s)

HEK293T cells (ATCC, cat. no. CRL-3216), Huh-7 cells (Japanese Collection of Research Bioresources [JCRB], cat. no. 0403)

Authentication

The authentication of cells have been confirmed using STR method

Mycoplasma contamination

All cell lines were tested negative for mycoplasma contanmination

Commonly misidentified lines

(See ICLAC register)

None 